\title{
РАЗВИТИЕ ИННОВАЦИОННЫХ ПРОМЫШЛЕННЫХ КЛАСТЕРОВ В УСЛОВИЯХ ЦИФРОВИЗАЦИИ ЭКОНОМИКИ ${ }^{1}$
}

\section{DEVELOPMENT OF INNOVATIVE INDUSTRIAL CLUSTERS IN THE CONTEXT OF DIGITALIZATION OF THE ECONOMY}

A. Dyrdonova

A. Shinkevich

L. Gorbach

Summary: The results of the author's research devoted to the development of innovative industrial clusters in the context of the digitalization of the economy are presented. The stages of creating clusters are proposed: assessment of economic prerequisites; determination of the structure of the cluster and its members; the formation of their economic motives; performance analysis. The main components of the mechanism for regulating the activity of an innovative industrial cluster are described. Indicators for assessing innovation in an industrial cluster are proposed.

Keywords: innovative industrial cluster, economic prerequisites for creation, structure, formation mechanism, development strategy, efficiency.
Дырдонова Алёна Николаевна

Д.э.н., дочент, Нижнекамский химико-технологический институт (филиал) ФГБОУ ВО «Казанский национальный исследовательский технологический университет» dan-home@yandex.ru

Шинкевич Алексей Иванович

Д.э.н., профессор, ФГБОУ ВО «Казанский национальный исследовательский технологический университет»

Горбач Людмила Анатольевна

К.э.н., дочент, ФГБОУ ВО «Казанский начиональный исследовательский технологический университет»

Аннотация: Изложены результаты авторского исследования, посвященного вопросам развития инновационных промышленных кластеров в условиях цифровизации экономики. Предложены этапы создания кластеров: оценка экономических предпосылок; определение структуры кластера и его участников; формирование их экономических мотивов; анализ эффективности функционирования. Описаны основные составляющие механизма регулирования деятельности инновационного промышленного кластера. Предложены показатели оценки инновационной деятельности в промышленном кластере.

Ключевые слова: инновационный промышленный кластер, экономические предпосылки создания, структура, механизм формирования, стратегия развития, эффективность.

Все вышесказанное является весомым обоснованием актуальности и практической значимости вопросов развития инновационных промышленных кластеров в условиях цифровой трансформации российской экономики.

Формирование и развитие инновационных промышленных кластеров в условиях цифровизации экономики, на наш взгляд, должно происходить поэтапно.

Первый этап включает анализ экономических предпосылок создания инновационного промышленного кластера, который будет включать исследование отрасли специализации (территории/региона) и наличия специализированных инструментов и форм государственной поддержки его развития. Здесь необходимо выявить не только наличие крупных промышленных предприятий (отраслевых доминант) и специализированных фирм (вспомогательных отраслей), но и важно рассмотреть:

- динамику взаимодействия крупных промышленных предприятий и малых фирм - потенциальных участников кластера, объемы их сделок; трансформации экономики в цифровой формат. 
- динамику кооперационного взаимодействия предприятий малого и среднего бизнеса;

- доступность необходимого квалифицированного труда и подвижность рынка трудовых ресурсов;

- востребованность единообразных сервисных бизнес-услуг для предприятий - участников кластера;

- развитие внутрифирменной кооперации и резервы повышения инновационной и экономической активности предприятий - участников кластера.

Второй этап заключается в определении участников промышленного инновационного кластера. Состав участников такого кластера предопределяется его специфическими характеристиками:

- инновационный промышленный кластер четко специализирован, поэтому базовыми участниками кластера будут являться крупные промышленные предприятия и фирмы, функционирующие на различных стадиях и режимах производства однородного продукта (работы, услуги);

- инновационный промышленный кластер обеспечивает перелив знаний и опыта. Овладение информацией, доступ к её источникам, развитие новых областей компетенций и трудовых навыков в условиях цифровизации экономики продуцирует становление цифровых технологий и их сочетание со способами гибкого производства. Знание и обучение становятся ключевыми факторами кон- курентоспособности [1] в кластере, поэтому в их составе будут институты, способные развивать и укреплять профессиональные связи и обмены;

- промышленный кластер инновационно активен, поэтому в его состав будут входить научные организации, малые инновационные предприятия, продуцирующие предпринимательскую деятельность.

Необходимо отметить, что функционирование кластера зависит от слаженности взаимодействия с институтами власти территории/региона [2], поэтому они также будут присутствовать в структуре кластера (рис. 1).

Третий этап заключается в выявлении заинтересованности участников и определении экономических мотивов вхождения в инновационный промышленный кластер (усиление преимуществ, рост конкурентоспособности, экономия издержек, извлечение дополнительной прибыли, повышение инновационной активности и пр.).

Четвертый этап заключается в формировании механизма создания и стратегии развития инновационного промышленного кластера, основанных на принципах консолидации всех ресурсов, объединения и усиления взаимодействия всех участников кластера, сотрудничества и согласования их интересов.

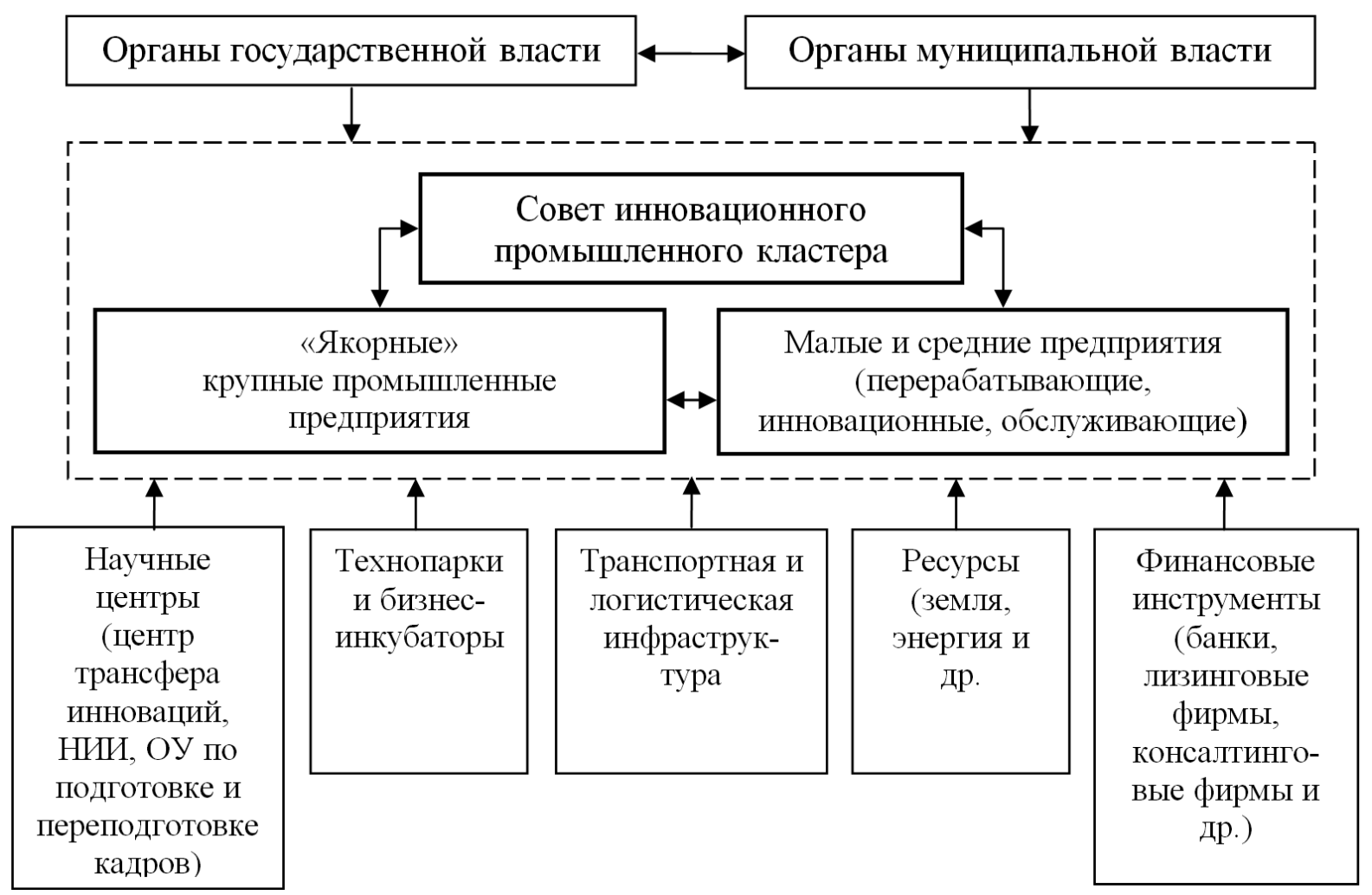

Рис. 1. Структура инновационного промышленного кластера [3] 
Механизм регулирования деятельности инновационного промышленного кластера, на наш взгляд, должен включать следующие меры, инструменты и мероприятия:

- организационно-политические меры: от формирования и периодической корректировки приоритетов территориального (регионального) научно-технического, технологического и инновационного развития до разработки и внедрения новых правовых документов по проблемам развития кластера;

- административно-организационные мероприятия: обеспечение условий интеграции участников кластера; развитие форм поддержки инновационного предпринимательства [4]; формирование и финансирование целевых программ и проектов по развитию кластера; совершенствование подготовки и переподготовки кадров в области управления инновациями и коммерциализации технологий; привлечение иностранных инвестиций и др.;

- финансовые инструменты: налоговое симулирование создание кластеров, инвестиционная поддержка новаций, созданных в кластере, налоговые скидки.

Стратегия развития инновационного промышленного кластера определяется исходя из соотношения начальных (входных) возможностей (материальных, технических, финансовых) кластера, территории/региона и государства в целом и достигаемых рубежей.

Пятый этап заключается в оценке эффективности формирования и развития инновационного промышленного кластера.
Ожидаемые результаты от создания кластера дифференцируются в зависимости от интересов его участников. Таким образом, показателями эффективности участия в кластерном образовании могут быть: динамика основных технико-экономических показателей финансово-хозяйственной деятельности участников кластера; увеличение доли инновационной продукции; увеличение объема привлекаемых инвестиций и другое.

К тому же, для оценки инновационной деятельности в промышленном кластере нами предлагается рассчитывать:

1. относительную эффективность инновационной деятельности промышленного кластера, которая будет определятся как отношение объема выпуска инновационной продукции в кластере к сумме затрат на приобретение инновационных технологий и затрат на производство и реализацию инновационной продукции.

2. рентабельность инновационной продукции, производимой в кластере которая будет определятся как отношение прибыли от реализации инновационной продукции к сумме затрат на приобретение инновационных технологий и затрат на производство и продажу инновационной продукции кластера.

Таким образом, реализация предложенных этапов формирования инновационных промышленных кластеров позволит максимально выгодно использовать созданные на определенной территории условия для кластеризации, сформировать структуру кластера и определить приоритеты его развития, оценить эффективность его функционирования и выработать стратегию дальнейшего роста.

\section{ЛИТЕРАТУРА}

1. Кудрявцева С.С., Неганов К.К. Научно-технический потенциал России как фактор экономического роста в экономике знаний // Экономический вестник Республики Татарстан. - 2016. - № 2. - С. 61-65.

2. Формирование промышленного кластера в экономике крупнейшего города / 0.А. Романова, А.В. Макаров, А.П. Петров. - М.: ЗАО «Издательство «Экономика», 2008. -133 c.

3. Дырдонова А.Н. Инфраструктурное обеспечение развития территориального кластера // Региональная экономика: теория и практика. - 2011 . - № 26 (209). - C. 30-36.

4. Шинкевич М.В., Барсегян Н.В. Роль предпринимательских инициатив в совершенствовании организации производства предприятий нефтехимического комплекса // Вестник Белгородского университета кооперации, экономики и права. - 2019. - №2. - С.358-369. 